\title{
Microstructural Characterization of Nonferrous Alloys for Antifriction Components
}

\author{
Cássio Barbosa*, Sheyla Santana de Carvalho, Ibrahim de Cerqueira Abud, Lisiane Gonçalves de Lima and Denise \\ Souza de Freitas
}

Instituto Nacional de Tecnologia (INT), Avenida Venezuela, Brazil

*Corresponding author: Cássio Barbosa, Instituto Nacional de Tecnologia (INT), Avenida Venezuela, Brazil

\begin{abstract}
In the last years the development of the mechanical and metallurgical industry has led to the search for materials with even better mechanical properties and corrosion resistance, with the purpose of withstanding severe conditions of use and thus assessing better performance for equipments and structures that use components fabricated with such materials, thereby requiring the characterization of the microstructure of these materials that influence considerably their properties. With this purpose, techniques such as optical microscopy, microhardness tests and scanning electron microscopy (SEM), comprising EDS (X ray energy dispersion spectroscopy), WDS (X ray wavelength dispersion spectroscopy) and EBSD (electron back scattering diffraction) analysis procedures were used to identify phases present in two nonferrous alloys used in the fabrication of antifriction components: aluminum-tin-silicon-copper $(\mathrm{Al}-\mathrm{Sn}-\mathrm{Si}-\mathrm{Cu})$ and copper-tin-bismuth $(\mathrm{Cu}-\mathrm{Sn}-\mathrm{Bi})$ alloys.
\end{abstract}

Keywords: Microstructural characterization; Aluminum alloys; Copper alloys; Friction

\section{Introduction}

Antifriction components are used in motors and other devices which are subjected to dynamic loading associated to severe friction conditions between metallic surfaces, such as bearing in contact with rotatory shafts. In these conditions, not only strength, but also an adequate sliding surface is essential in order to minimize friction with the rotative or any other mechanical element which transmits mechanical loads which demands considerable wear and fatigue resistance together with adequate lubricity which can assess slipping between shaft, or equivalent component, and bearing or similar supporting element. Along several decades the evolution of the automotive industry has led to the development of aluminum and copper based alloys with elements that can improve lubricity and strength. This is the case of $\mathrm{Al}-\mathrm{Sn}-\mathrm{Si}-\mathrm{Cu}$ and $\mathrm{Cu}-\mathrm{Sn}-\mathrm{Bi}$ alloys that present a favorable combination of adequate strength and lubricity for this type of application. Al-Sn-Si-Cu alloys have an aluminum rich matrix with moderate strength with dispersed soft particles of a secondary phase which is essentially tin. These particles improve the ubricity, the formability and the ability of such material to absorb particles, also known as embedabilty. Furthermore, these antifriction components must also support heavy cyclic loading (fatigue), corrosion and temperatures above $150^{\circ} \mathrm{C}$ in this type of application [1]. Al-Sn based alloys have limited fatigue resistance, thus needing the addition of other elements, such as around $1 \%$ copper (in mass \%) for strengthening the aluminum rich matrix, through substitutional solid solution or precipitation hardening provided by the formation of intermetallic particles, such as $\mathrm{Al}_{2} \mathrm{Cu}$ type, and silicon, which also provides solid solution strengthening and the formation of hard dispersed silicon particles, which enhance wear resistance.

Without these alloying elements, Al-Sn alloys would present low wear resistance, in spite of their high lubricity. On the other hand, Al-Si alloys, with good mechanical properties, do not present good lubricity. Therefore, Al-Sn-Si alloys show better tribological behavior than Al-Sn and Al-Si alloys, due to the synergistic effect of hard silicon particles surrounded by a soft and lubricant tin rich phase. In these alloys the tin contents vary between 10 and 20 $\%$ and the silicon contents between 2 and $11 \%$ (in mass \%) [2]. The main effect of tin as alloying element is its lubrication action, whereas silicon hardens the material, thus enhancing its wear resistance. The tribological properties of Al-Sn-Si alloys are superior when compared with both Al-Sn and Al-Si alloys, mainly in engines subjected to higher loads and speeds. The microstructure of these 
Al-Sn-Si alloys is different from the ones of the other two types of alloys, for showing a special eutectic phase composed by silicon particles embedded in tin, being these mixed particles distributed in the aluminum rich matrix. Due to this specific feature this type of alloy presents relatively high hardness combined with good lubrication capacity. Therefore, the wear rate increase associated with load enhancement is lower in Al-Sn-Si in comparison with both $\mathrm{Al}-\mathrm{Sn}$ and $\mathrm{Al}-\mathrm{Si}$ alloys. Intermetallic phases are not often found in $\mathrm{Al}-$ Sn-Si alloys, but the copper content is sufficient to form significant amounts of $\mathrm{Al}_{2} \mathrm{Cu}$ phase. If the tin content is very high, the corrosion resistance of the Al-Sn alloys will be decreased. Tin atoms can be introduced in the $\mathrm{Al}_{2} \mathrm{O}_{3}$ lattice, thus enhancing the concentration of point shaped defects in this lattice, leading to rapid corrosion attack of the alloy. Usually the coarser dendritic microstructure presents larger areas with higher contents of tin. For aluminum alloys used for this type of application a careful analysis of localized corrosion resistance (pitting and other types) is very important [3]. Some properties are essential for material used in antifriction components such as bearings: fatigue resistance, formability, corrosion resistance, compatibility (gripping resistance), wear resistance, embedabilty (capacity of absorption of particles) and cavitation resistance [4].

The introduction of copper and magnesium in Al-Si alloys enhance their hardness and wear resistance. Silicon contributes to improve their strength. Higher silicon and tin contents together favor the improvement of wear resistance in these alloys [5]. AlSn binary system presents low miscibility of tin in aluminum below $0.09 \%$ (in mass). When tin contents are higher than 0.09 $\%$ (in mass) a heterogeneous microstructure prevails with tin rich particles distributed in an aluminum rich matrix. Such alloys present a heterogeneous microstructure with tin rich particles randomly distributed in a continuous aluminum rich matrix. Therefore, this combination provides simultaneously the lubrication capacity of tin together with better strength and toughness provided by the aluminum rich matrix [6,7]. In the Al-Sn-Si alloys initially the primary grains of aluminum are separated from the liquid phase, and then the binary eutectic is formed: $\mathrm{L} \rightarrow \mathrm{Al}+\mathrm{Si}$, leading to the enhancement of the tin concentration in the liquid with the reduction of temperature. Finally, the reaction which leads to the formation of the ternary eutectic starts at around $225^{\circ} \mathrm{C}: \mathrm{L} \rightarrow \mathrm{Al}+$ $\mathrm{Si}+\mathrm{Sn}$. The tin and silicon contents can influence the temperature of the onset of the formation of primary aluminum rich grains and the binary eutectic [8]. Bismuth has replaced lead as antifriction element due to the toxic effect of lead on the human health, which has limited its application in many products, mainly related to lead vapor inhalation during solid-liquid phase transformations such as the ones involved in some industrial fabrication processes such as welding and casting. According to the literature, the interface between copper and the eutectic phase Sn-Bi shows both a dark contrast due to the presence a tin rich phase and also some brighter contrast due to the presence of the bismuth rich phase. On the interface tin reacts with copper to form a fine layer of an intermetallic compound: $\mathrm{Cu}_{6} \mathrm{Sn}_{5}$ (n phase) with thickness around 1.2 $\mu \mathrm{m}$. This layer can undergo ageing which leads to the growth of this thickness to $6 \mu \mathrm{m}$. There is also a very fine (thickness around 0,5 $\mu \mathrm{m}$ ) layer of another intermetallic compound known as $\mathrm{Cu}_{3} \mathrm{Sn}$, also named $\varepsilon$ phase, which is formed copper and $\eta$ phase. This layer can only be observed with higher magnifications in a scanning electron microscope (SEM) [9].

The preferential depletion of tin to form the coarse $\eta$ phase leads to the formation of network of bismuth rich phase on the interfaces between matrix and intermetallic $\mathrm{Cu}-\mathrm{Sn}$ particles [10]. According to the literature, bismuth dos not form intermetallic phases with tin and presents very limited solubility in this element and in the intermetallic compound particles of $\mathrm{Cu}-\mathrm{Sn}$ as well. Bismuth is seen predominantly in the double phase eutectic. Likewise lead in other alloys, bismuth is also accumulated on the interface between the intermetallic $\mathrm{Cu}$-Sn compound and the matrix. However, bismuth is harder and more brittle than lead, presenting a somehow different effect on the properties of these materials. Bismuth can cause grain boundary embrittlement in copper and its alloys [10]. If the bismuth content is higher (above $5 \%$, for instance), it can contribute to the formation of very coarse particles, therefore harming the mechanical properties of the material [11]. When this bronze is exposed to plain atmosphere for long periods, a protective oxide layer is formed in its surface, a phenomenon known as passivation. This protective layer can minimize the occurrence of corrosion, but the presence of sulfide or chloride compounds, that accelerate the corrosion process [8]. In general, tin bronzes present good strength and hardness combined with good ductility, but if bismuth is added in high contents (above $5 \%$ ), it forms coarse particles, therefore harming the mechanical properties. Nevertheless, the presence of other alloying elements can change the segregation behavior of bismuth in copper alloys [11].

\section{Materials and Experimental Methodology}

Table 1 presents the nominal chemical composition of both aluminum and copper alloys used in antifriction components.

Table 1: Nominal chemical composition of aluminum and copper alloys used in antifriction components.

\begin{tabular}{|c|c|c|c|c|c|c|c|c|c|c|}
\hline Alloy & Element & Sn & Si & Mn & Bi & Ni & Fe & Pb & Cu & Al \\
\hline Al-Sn-Si-Cu & Mass \% & 20.18 & $2 . .7$ & 1.05 & --- & --- & -- & -- & 1.01 & Balance \\
\hline Cu-Sn-Bi & Mass $\%$ & 4 & --- & --- & 4 & 1 & 0.7 max & 0.1 max & Balance & -- \\
\hline
\end{tabular}


Three types of analyses were performed: optical microscopy, comprising visual analysis in a stereomicroscope, micro hardness tests and scanning electron microscopy (SEM). Samples were subjected to conventional metallographic preparation: cutting, mounting, grinding (220 to 1200 mesh: silicon carbide paper) and polishing (diamond past with different grain size in sequence: 6 $\mu \mathrm{m}, 3 \mu \mathrm{m}$ e $1 \mu \mathrm{m}$ ) [12-14]. The Al-Sn-Si-Cu sample was etched with Keller solution: $1 \mathrm{ml}$ hydrofluoric acid (HF), $15 \mathrm{ml}$ hydrochloric $(\mathrm{HCl}), 25 \mathrm{ml}$ nitric acid $\left(\mathrm{HNO}_{3}\right)$ and $50 \mathrm{ml}$ water $\left(\mathrm{H}_{2} \mathrm{O}\right)$. The micrographic images were obtained with an optical microscope: Olympus, BX 51M model. The same samples were analyzed in a scanning electron microscope with field emission gun (FESEM) manufactured by FEI: Quanta FEG 450 model operating at 20 or $30 \mathrm{kV}$, with a X ray energy dispersion spectroscopy (EDS) detector for chemical microanalysis and a EBSD (electron back scattering diffraction) detector for crystallographic analysis. Just in case of doubts about chemical composition of some phase in some micro regions, the $\mathrm{X}$ ray wavelength energy dispersion spectroscopy (WDS) was also used, since, in spite of its higher accuracy, it is a more complex and time-consuming technique. Microhardness was evaluated for both materials: Vickers scale with $25 \mathrm{gf}$ load (about $0.245 \mathrm{~N}$ ) in equipment fabricated by Akashi: model $400-\mathrm{M}-\mathrm{H}$, according to ISO (International Organization for Standardization) 6507-1 standard [15].

\section{Results}

The microstructure of Al-Sn-Si-Cu alloy, as revealed by optical microscopy, is presented in Figure 1.

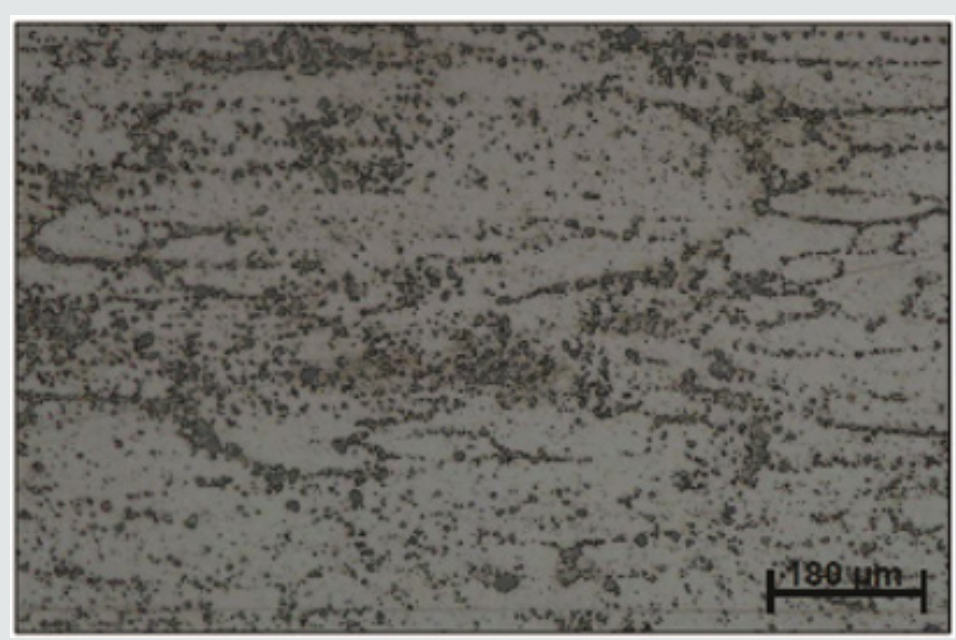

Figure 1: The microstructure of Al-Sn-Si-Cu alloy. as revealed by optical microscopy.

SEM images of the same ample are presented in Figures 2-4, as well as EDS spectra and EDS spectra of the Al-Sn-Si-Cu alloy (Figures $3,4)$.

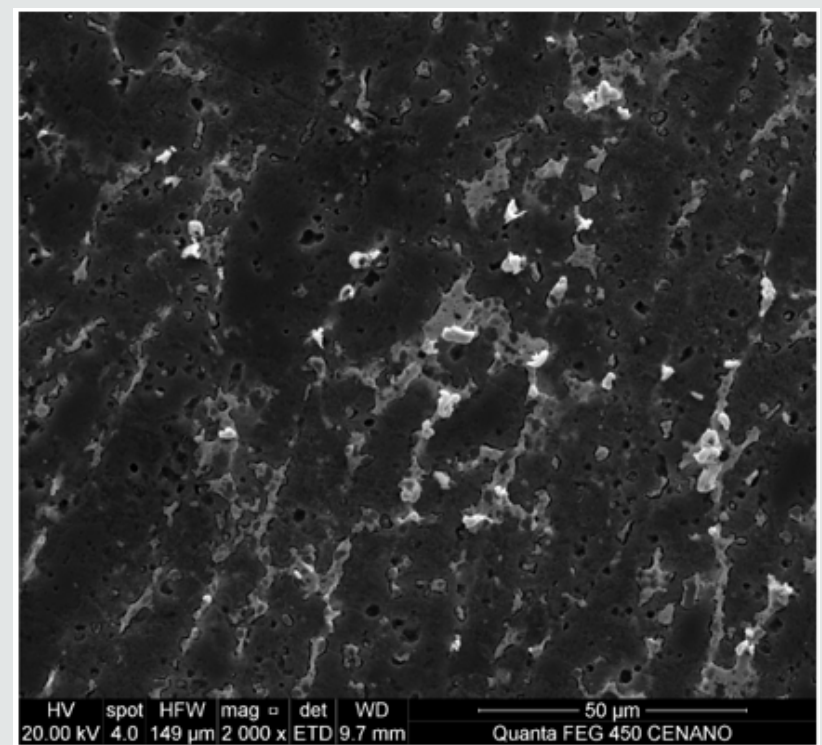

Figure 2: SEM image: overview on the microstructure of the Al-Sn-Si-Cu alloy. Dark background: aluminum rich matrix. Bright coarser particles: tin rich phase. while smaller medium gray particles are a silicon rich phase. 


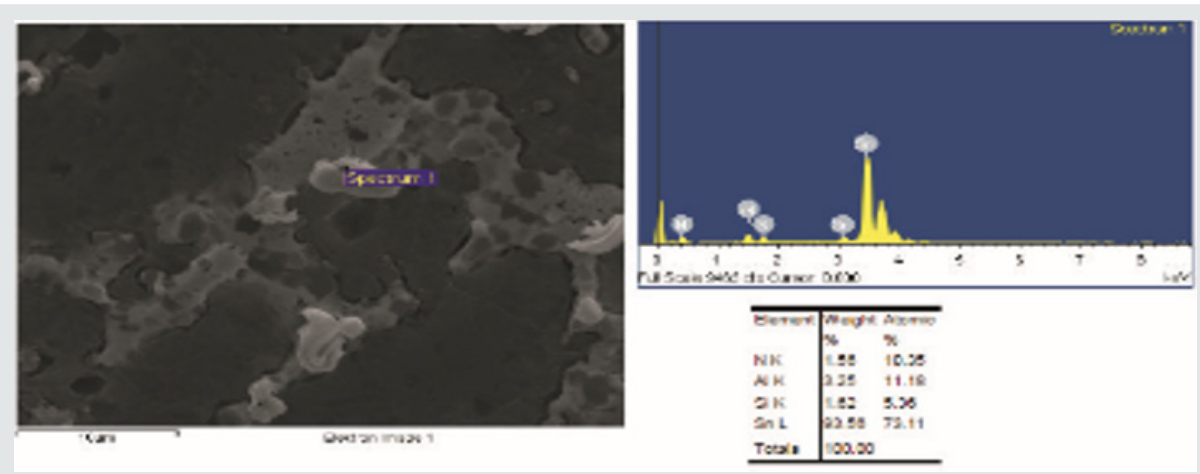

Figure 3: SEM image and EDS: spectrum: Sn particle.
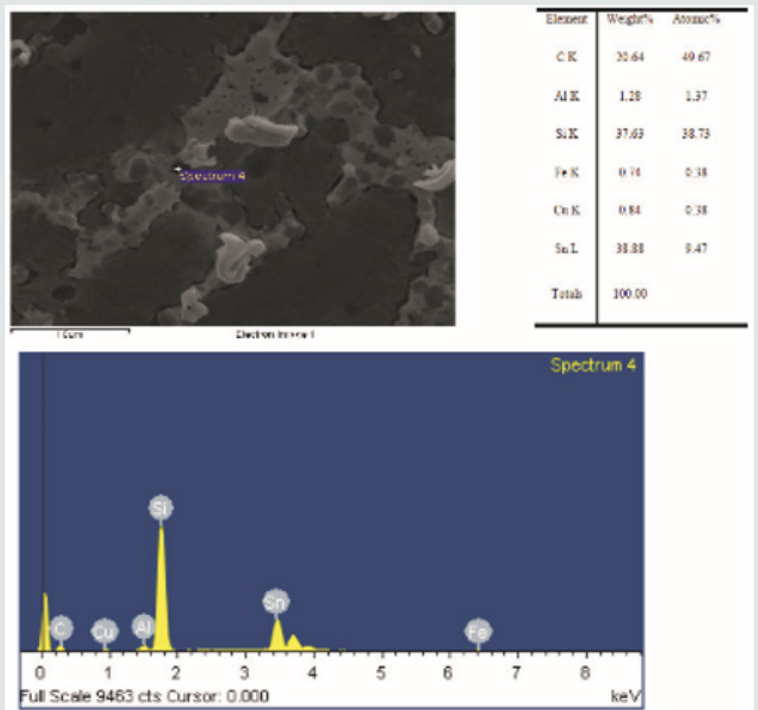

Figure 4: SEM image and EDS: spectrum: Si particle.

Figure 5 presents smaller particles with medium to dark grayscale levels that are silicon rich and surround by brighter particles, which correspond to a tin rich phase. This configuration has been mentioned in the technical literature as a positive characteristic, since it combines the hardness/wear resistance of silicon rich phases with lubricity/low friction coefficient of tin rich phases [2].

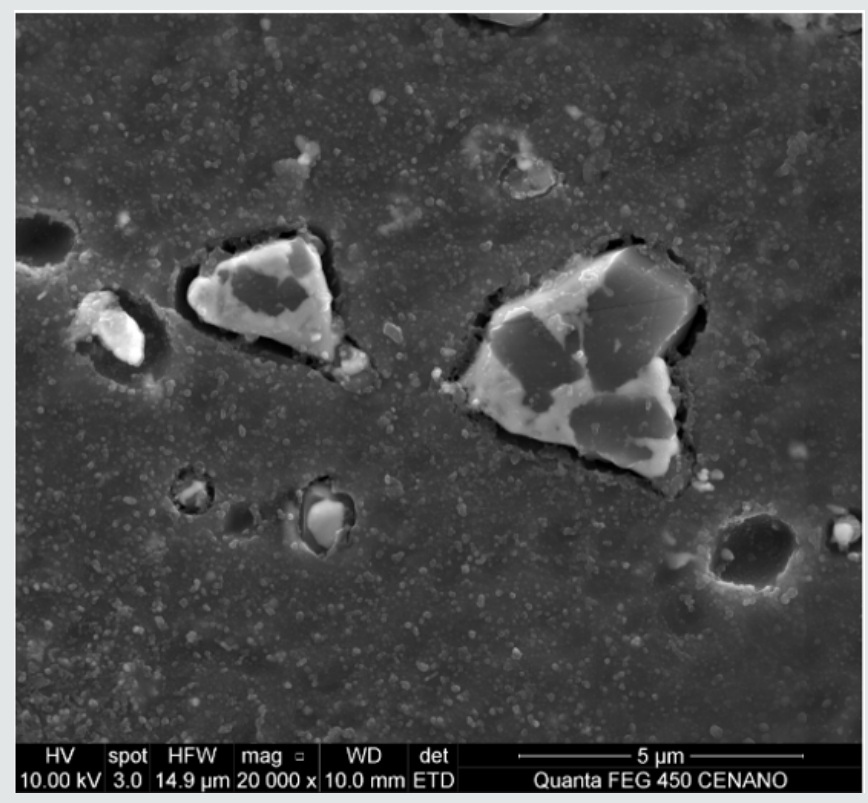

Figure 5: SEM image: Si particle surrounded by Sn particle. 
A EBSD map of identification of phases present in the Al-Sn-Si-Cu alloy is shown in Figure 5 \& Figure 6.

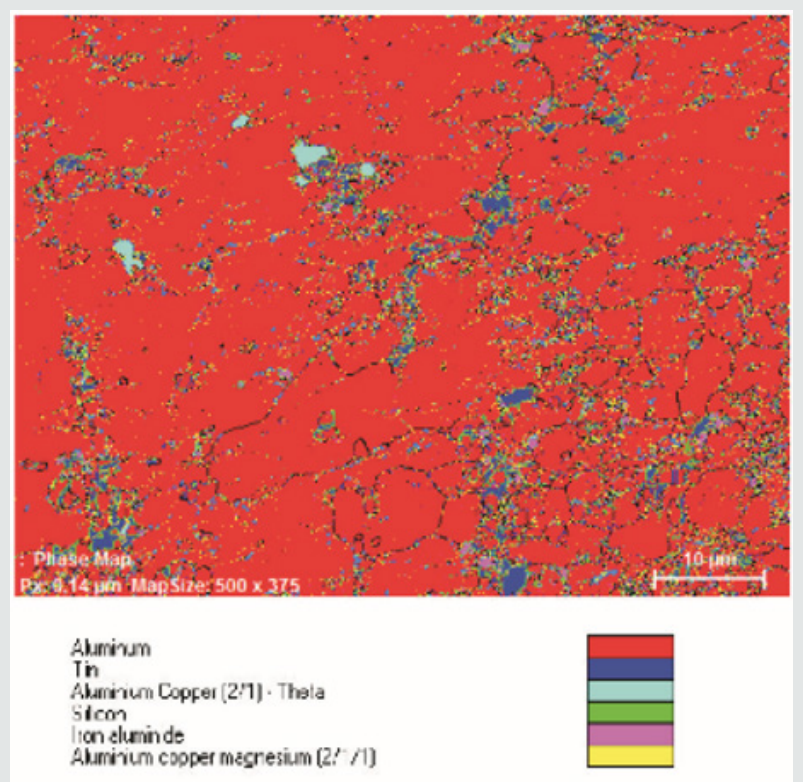

Figure 6: EBSD map: identification of phases present in the Al-Sn-Si-Cu alloy.

Table 2 presents microhardness values (Vickers scale) obtained with a 25 gf (0,245 N) load in the aluminum rich matrix and in the tin rich coarser secondary phase particles.

Table 2: Microhardness in the matrix and the coarser secondary phase particles present in the Al-Sn-Si-Cu alloy.

\begin{tabular}{|c|c|c|}
\hline Region & Matrix (HV0.25) & Particles (HV0.25) \\
\hline 1 & 74 & 62 \\
\hline 2 & 71 & 54 \\
\hline 3 & 76 & 61 \\
\hline 4 & 77 & 63 \\
\hline 5 & 75 & 61.6 \\
\hline
\end{tabular}

The microstructure of the Cu-Sn-Bi alloys, as revealed by optical microscopy, is presented in Figure 7.

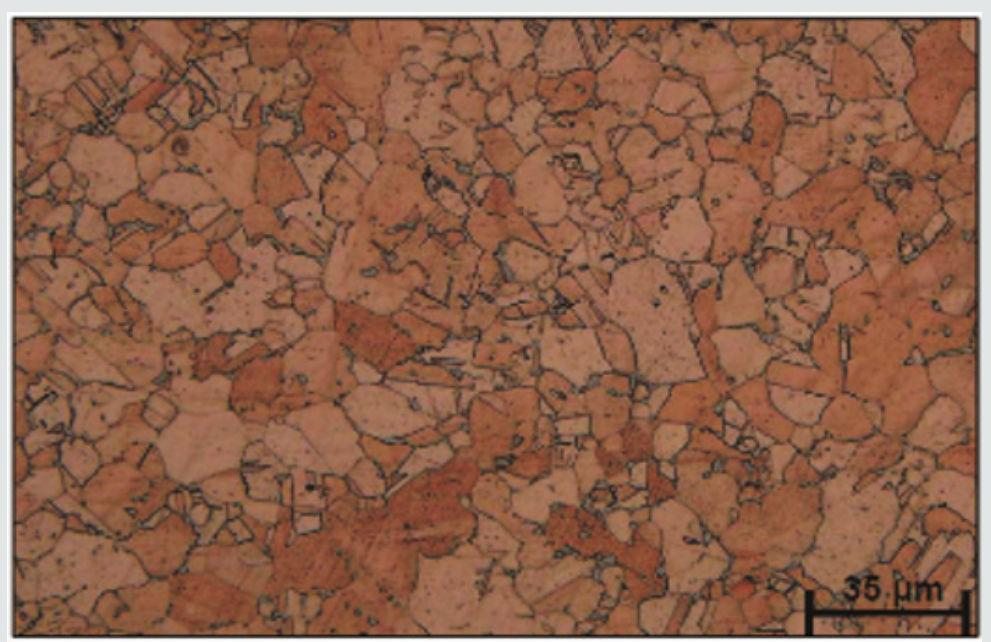

Figure 7: Microstructure of $\mathrm{Cu}-\mathrm{Sn}-\mathrm{Bi}$ alloy as revealed by optical microscopy. Etchant: $\mathrm{FeCl} 3$ and $\mathrm{HCl}$ in ethanol.

Figures 8 and 9 show a SEM aspect and EDS spectrum of the $\mathrm{Cu}-\mathrm{Sn}-\mathrm{Bi}$ alloy, respectively, revealing that the bright particles correspond to a bismuth rich phase, preferentially located on the grain boundaries of the $\mathrm{Cu}-\mathrm{Sn}$ matrix, comprising also triple point boundaries. 


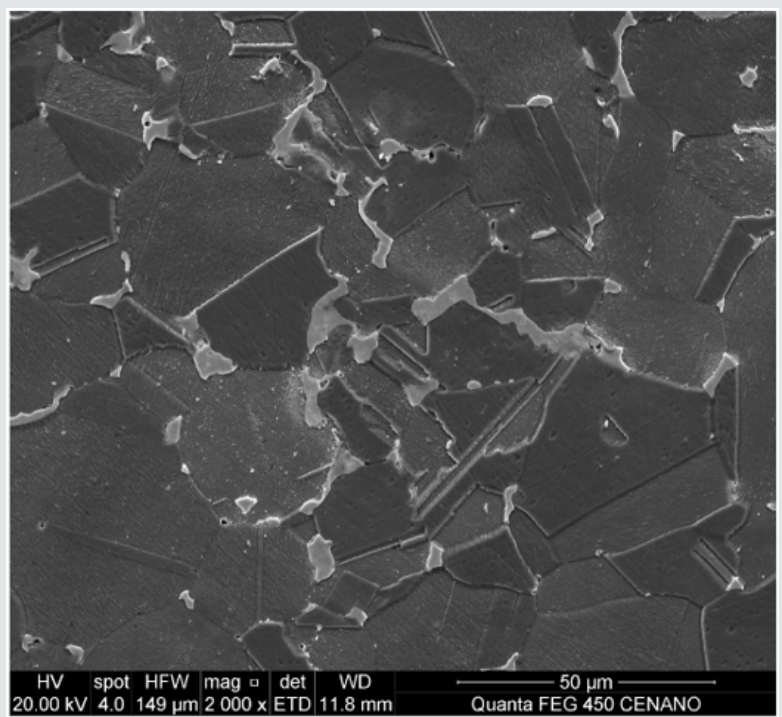

Figure 8: SEM image: microstructure of a Cu-Sn-Bi alloy. showing a dark matrix (bronze: $\mathrm{Cu}-\mathrm{Sn}$ ) and brighter particles: bismuth.
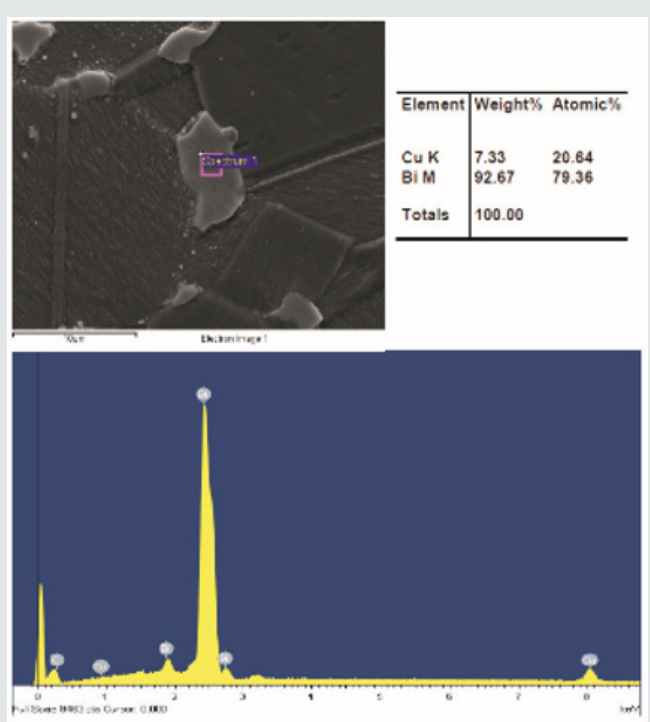

Figure 9: SEM image and EDS spectrum: bismuth particle.

Figure 10 shows a small particle, which was identified by EDS analysis (Figure 11) as a copper rich phase.

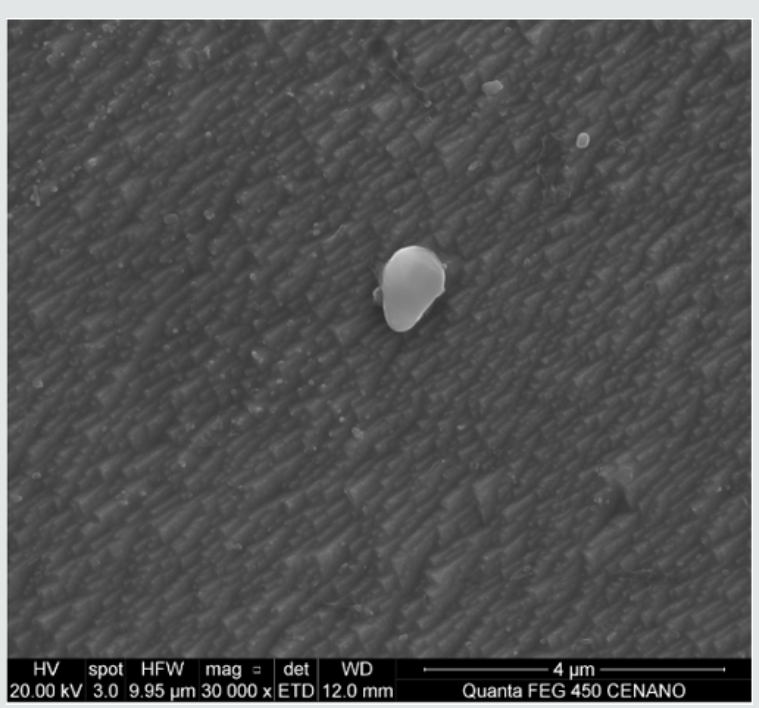

Figure 10: SEM image: small particle. which was later identified as a copper rich phase. 

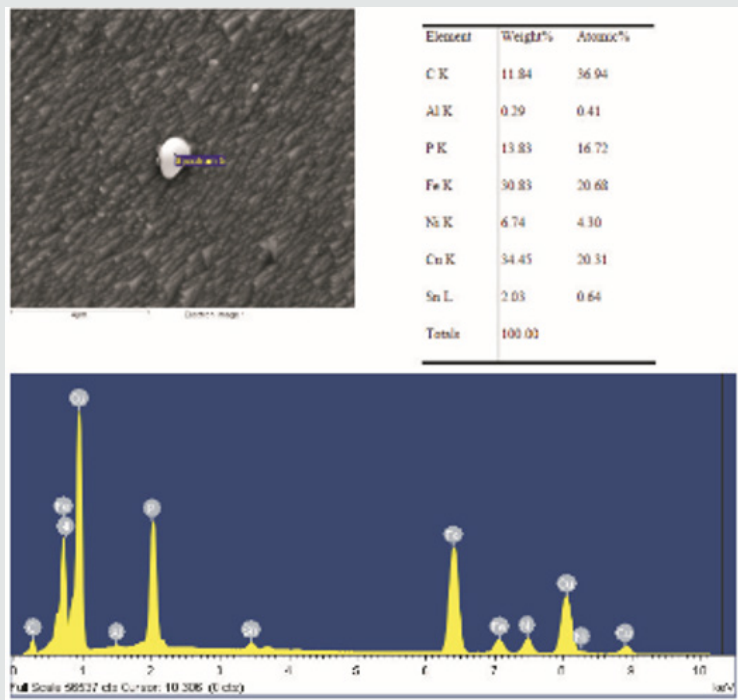

Figure 11: EDS spectrum: small particle. later identified as a copper rich phase.

Figure 12 presents a EBSD map of the same sample, which confirms the bronze (Cu-Sn) matrix with coarser grains, corresponding to the blue color, whereas the bismuth particles are shown in yellow color in the same map. Additionally, the previously observed small particles are indicated as copper phase by the red colored dots both inside the matrix grains and on its grain boundaries.

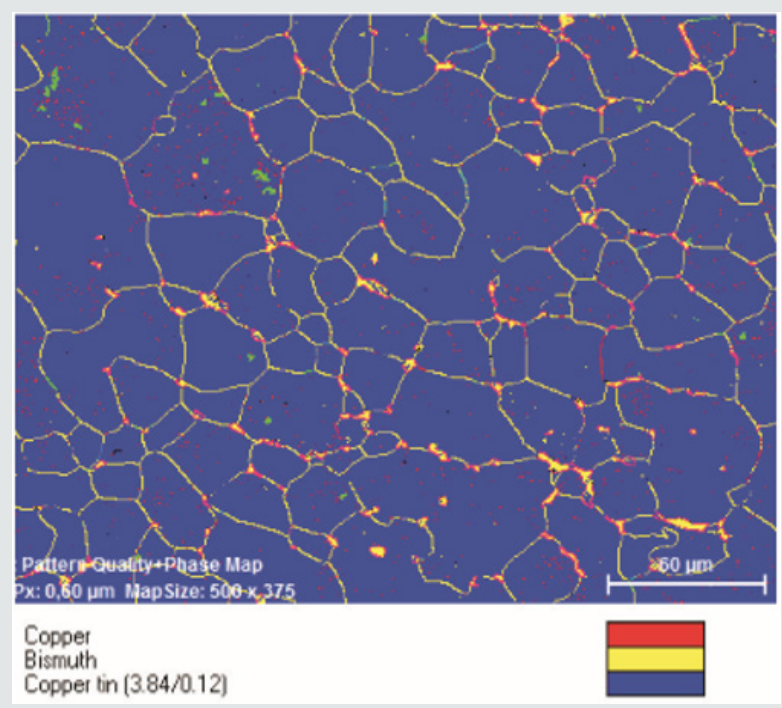

Figure 12: EBSD phase identification map of $\mathrm{Cu}-\mathrm{Sn}$-Bi alloy.

Table 3 presents microhardness values (Vickers scale: HV) obtained with a 25 gf $(0,245 \mathrm{~N})$ load in the copper-tin (bronze) rich matrix and in the bismuth rich coarser secondary phase particles.

Table 3: Microhardness in the matrix and the coarser secondary phase particles present in the Cu-Sn-Bi alloy.

\begin{tabular}{|c|c|c|}
\hline Region & Matrix (HV0.25) & Particles (HV0.25) \\
\hline 1 & 94 & 86 \\
\hline 2 & 109 & 85 \\
\hline 3 & 102 & 86 \\
\hline 4 & 98 & 86 \\
\hline 5 & 95 & 85.2 \\
\hline
\end{tabular}

The WDS spectra of five copper rich particles (1, 2 and 3) of the Cu-Sn-Bi alloy sample are presented in Figures 13-15. 


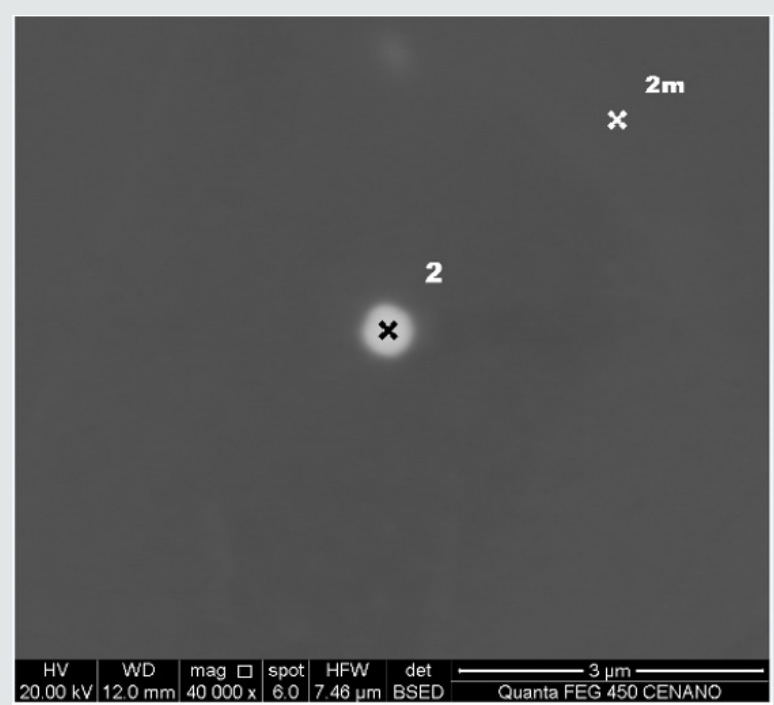

Figure 13: Particle 1 analyzed by WDS.

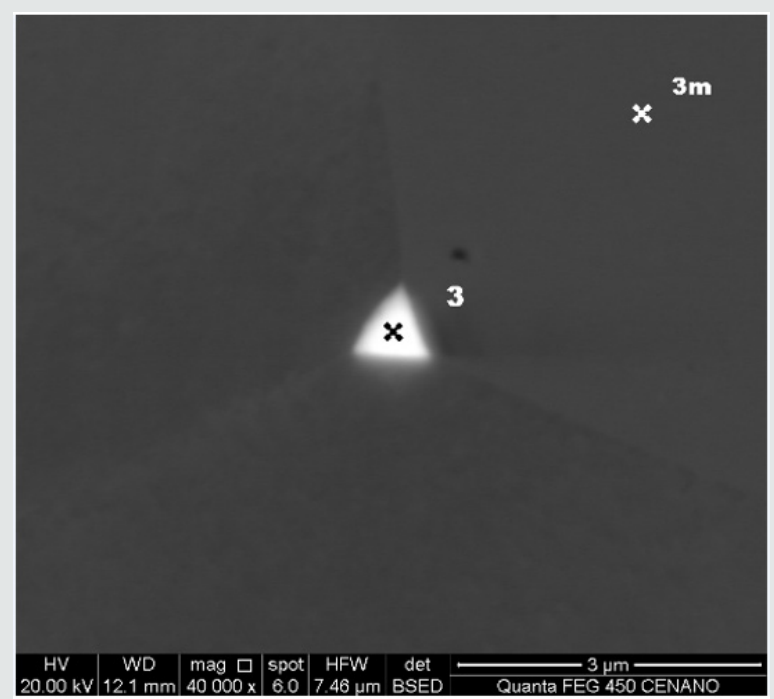

Figure 14: Particle 2 analyzed by WDS.

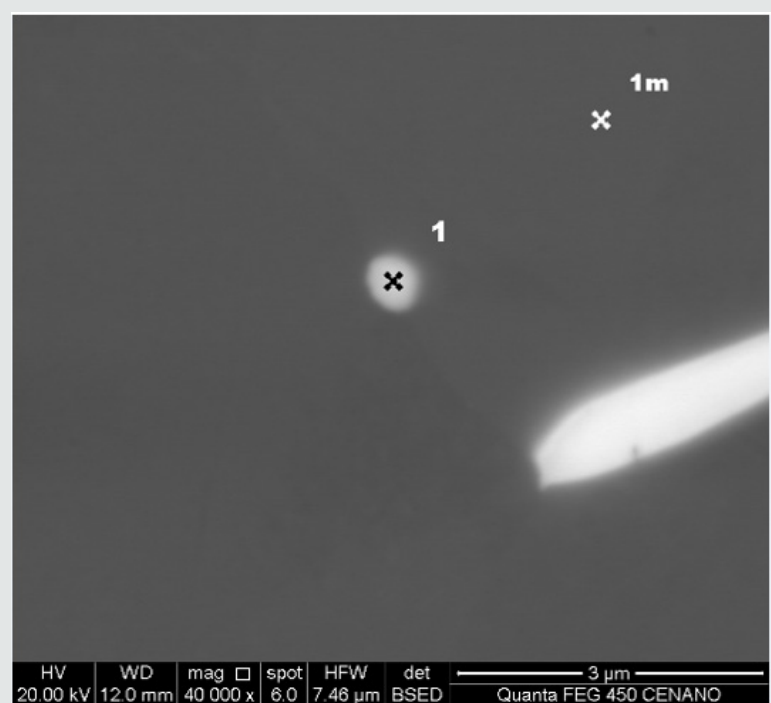

Figure 15: Particle 3 analyzed by WDS. 
The corresponding quantitative WDS results are presented in Tables 4-6, together with some results of the surrounding matrix for comparison.

According to the WDS results, it can be observed that in these samll copper rich particles only copper and bismuth contents are Table 4: WDS quantitative analysis results of particle 1 . really significant, meaning that the contents of other elements are probably the consequence of the effect of the surrounding matrix. For this reaon, Table 7 presents the corrected (only the two elements are considered in the particle) results of copper and bismuth atomic fraction contents for each particle and their average value.

\begin{tabular}{|c|c|c|c|c|c|}
\hline \multicolumn{6}{|c|}{ Particle 1} \\
\hline Element & k Ratio & Weight $\%$ & Weight $\%$ Sigma & Intensity Corrn. & Atomic\% \\
\hline $\mathrm{Ni} \mathrm{Ka}$ & 0.00584 & 0.492 & 0.023 & 1.0569 & 0.544 \\
\hline $\mathrm{Fe} \mathrm{Ka}$ & 0.00381 & 0.336 & 0.018 & 1.0106 & 0.39 \\
\hline Sn La & 0.02344 & 2.758 & 0.045 & 0.7578 & 1.507 \\
\hline Bi Ma & 0.19993 & 23.762 & 0.225 & 0.7502 & 7.372 \\
\hline P Ка & 0.00062 & 0.016 & 0.006 & 1.0929 & 0.032 \\
\hline $\mathrm{Cu} \mathrm{La}$ & 0.47597 & 68.476 & 0.321 & 0.6198 & 69.876 \\
\hline О Ка & 0.02716 & 1.62 & 0.052 & 0.5932 & 6.565 \\
\hline $\mathrm{C} \mathrm{Ka}$ & 0.00478 & 2.54 & 0.338 & 0.1678 & 13.714 \\
\hline Totals & & 100 & & & \\
\hline
\end{tabular}

Table 5: WDS quantitative analysis results of the particle 2 and the matrix $(2 \mathrm{~m})$.

\begin{tabular}{|c|c|c|c|c|c|}
\hline \multicolumn{6}{|c|}{ Particle 2} \\
\hline Element & k Ratio & Weight $\%$ & Weight $\%$ Sigma & Intensity Corrn. & Atomic\% \\
\hline $\mathrm{Ni} \mathrm{Ka}$ & 0.00712 & 0.577 & 0.023 & 1.0624 & 0.678 \\
\hline $\mathrm{Fe} \mathrm{Ka}$ & 0.0051 & 0.432 & 0.02 & 1.0157 & 0.534 \\
\hline Sn La & 0.01977 & 2.25 & 0.04 & 0.7563 & 1.308 \\
\hline Bi Ma & 0.21214 & 24.39 & 0.221 & 0.7489 & 8.054 \\
\hline P Ка & 0.00132 & 0.032 & 0.006 & 1.0888 & 0.071 \\
\hline $\mathrm{Cu} \mathrm{La}$ & 0.50368 & 69.569 & 0.295 & 0.6234 & 75.556 \\
\hline О Ка & 0.02474 & 1.396 & 0.048 & 0.6055 & 6.023 \\
\hline C Ka & 0.0026 & 1.353 & 0.286 & 0.1657 & 7.775 \\
\hline Totals & & 100 & & & \\
\hline \multicolumn{6}{|c|}{ Matrix (2m) } \\
\hline Element & k Ratio & Weight $\%$ & Weight $\%$ Sigma & Intensity Corrn. & Atomic\% \\
\hline $\mathrm{Ni} \mathrm{Ka}$ & 0.01112 & 1.051 & 0.031 & 1.0403 & 1.099 \\
\hline $\mathrm{Fe} \mathrm{Ka}$ & 0.00621 & 0.602 & 0.023 & 1.0138 & 0.662 \\
\hline Sn La & 0.02749 & 3.241 & 0.049 & 0.8342 & 1.676 \\
\hline Bi Ma & 0.00013 & 0.019 & 0.035 & 0.6781 & 0.006 \\
\hline P Ка & 0.00033 & 0.011 & 0.006 & 0.9253 & 0.021 \\
\hline $\mathrm{Cu} \mathrm{La}$ & 0.81581 & 93.924 & 0.309 & 0.8543 & 90.76 \\
\hline О Ка & 0.00164 & 0.089 & 0.04 & 0.7165 & 0.343 \\
\hline C Ka & 0.0015 & 1.063 & 0.315 & 0.1384 & 5.432 \\
\hline Totals & & 100 & & & \\
\hline
\end{tabular}

Table 6: WDS quantitative analysis results of the particle 3 and the matrix $(3 \mathrm{~m})$.

\begin{tabular}{|c|c|c|c|c|c|}
\hline \multicolumn{9}{|c|}{ Particle 3 } & Atomic\% \\
\hline Element & k Ratio & Weight\% & Weight\% Sigma & Intensity Corrn. & 1.422 \\
\hline Ni Ka & 0.01373 & 1.137 & 0.03 & 1.0709 & 1.0184 \\
\hline Fe Ka & 0.01118 & 0.974 & 0.026 & 0.7355 & 2.143 \\
\hline Sn La & 0.02873 & 3.465 & 0.051 & 0.7788 & 11.616 \\
\hline Bi Ma & 0.29023 & 33.067 & 0.248 & & \\
\hline
\end{tabular}




\begin{tabular}{|c|c|c|c|c|c|}
\hline $\mathrm{P} \mathrm{Ka}$ & 0.00051 & 0.012 & 0.005 & 1.1595 & 0.029 \\
\hline $\mathrm{Cu} \mathrm{La}$ & 0.35053 & 58.121 & 0.287 & 0.535 & 67.148 \\
\hline О Ка & 0.03485 & 2.194 & 0.058 & 0.5592 & 10.068 \\
\hline $\mathrm{C} \mathrm{Ka}$ & 0.00207 & 1.03 & 0.283 & 0.1787 & 6.294 \\
\hline Totals & & 100 & & & \\
\hline \multicolumn{6}{|c|}{ Matrix 3m } \\
\hline Element & k Ratio & Weight $\%$ & Weight $\%$ Sigma & Intensity Corrn. & Atomic\% \\
\hline $\mathrm{Ni} \mathrm{Ka}$ & 0.00858 & 0.819 & 0.028 & 1.0424 & 0.878 \\
\hline $\mathrm{Fe} \mathrm{Ka}$ & 0.0046 & 0.452 & 0.021 & 1.0139 & 0.51 \\
\hline Sn La & 0.03559 & 4.236 & 0.056 & 0.8359 & 2.248 \\
\hline Bi Ma & 0.00007 & 0.011 & 0.036 & 0.679 & 0.003 \\
\hline $\mathrm{Cu} \mathrm{La}$ & 0.79764 & 93.8 & 0.291 & 0.8461 & 92.996 \\
\hline $\mathrm{O} \mathrm{Ka}$ & 0.00295 & 0.166 & 0.041 & 0.7016 & 0.653 \\
\hline $\mathrm{C} \mathrm{Ka}$ & 0.00072 & 0.517 & 0.295 & 0.1392 & 2.712 \\
\hline Totals & & 100 & & & \\
\hline
\end{tabular}

Table 7: WDS quantitative analysis: corrected results of copper and bismuth atomic fraction contents for each particle (1 to 3$)$ and their average value.

\begin{tabular}{|c|c|c|c|c|c|}
\hline Particle & Mass \% Cu & Mass \% Bi & Mass \% Cu+Bi & Corrected \% Cu & Corrected \% Bi \\
\hline P1 & 69.88 & 7.37 & 77.25 & 90.46 & 9.54 \\
\hline P2 & 75.56 & 8.05 & 83.61 & 90.37 & 9.63 \\
\hline P3 & 67.15 & 11.61 & 78.76 & 85.26 & 14.74 \\
\hline Average & 70.86 & 9.01 & 79.87 & 88.7 & 11.3 \\
\hline Standard deviation & 4.29 & 2.28 & 3.32 & 2.98 & 2.98 \\
\hline
\end{tabular}

These results showed that the average composition of these particles would be $88.70 \%$ of copper and $11.30 \%$ in atomic fraction, with small variation (around $3 \%$ ), thus leading to the probable soichiometry of $\mathrm{Cu}_{9} \mathrm{Bi}$ for thse particles.

\section{Discussion}

The Al-Sn-Si-Cu analyzed in this study is used in several antifriction applications and in its microstructure it presents different phases as particles which are distributed throughout the aluminum rich matrix. as observed by optical and scanning electron microscopy (SEM). SEM/EDS analysis enabled the observation of these phases with further detail. as well as the determination of its chemical composition. Thus. it was observed that the coarser and brighter particles correspond to a tin rich phase. whereas the smaller and darker ones were identified as a silicon rich phase. Optical microscopy images reveal opposite contrast. showing dark tiny particles in a bright aluminum matrix [1.7.8]. Very often these silicon particles are embedded in the tin rich phase. Thus combining the hardening/strengthening effect of silicon with the lubricant/ antifriction action of tin. The ideal Sn/Si ratio is around 3 or 4 . because at this level it provides relatively high volume fraction and uniform microstructure with dispersed particles [8]. EBSD analysis complemented the information obtained by optical microscopy and SEM/EDS. since besides the coarse tiny particles and fine silicon particles. it also identified other secondary phases. also present as dispersed fine particles. such as $\mathrm{Al} 2 \mathrm{Cu}(\theta) . \mathrm{Al}_{2} \mathrm{CuMg}(\mathrm{S})$ and
Al3Fe. Anyway. these phases can contribute to strength increase. in the same sense as silicon phase. Microhardness test results confirm that tin rich secondary phase particles are considerably softer $(61.60 \mathrm{HV})$ than the aluminum rich matrix (74.60). Optical microscopy images revealed that $\mathrm{Cu}-\mathrm{Sn}$-Bi alloys contains relatively coarse particles distributed mainly on the grain boundaries of the matrix.

Scanning electron microscopy (SEM) analysis. comprising $\mathrm{X}$-ray energy dispersion spectroscopy (EDS) identified these coarse particles as bismuth phase. The same techniques. with larger magnifications allowed the identification of much smaller particles as a copper rich phase. Electron back scattering diffraction (EBSD) analysis confirmed the identification of these phases. The existence of these small copper rich particles has not been reported in the specific technical literature. but two different techniques (EDS and EBSD) confirmed the presence of such particles. Due to this doubt about the chemical composition of these small copper rich particles the WDS detector was used to help the identification of their chemical composition. The quantitative WDS results showed that these small copper rich particles can be expressed by an usual stoichiometry: Cu9Bi. The technical literature about the copperbismuth system says that in thermodinamical equilibrium both elements are immiscible in each other [16-20], but it also reports that metastable phases of the type CuXBiY can appear in the $\mathrm{Cu}$ Bi system, such as $\mathrm{Cu} 5 \mathrm{Bi} 2$ [16] and $\mathrm{Cu}_{3} \mathrm{Bi}$ [19]. Metastable phases in different metallic alloys/systems are reported in many classic 
texts of materials science about phase transformations [21,22], moreover in non-equilibrium conditions such as the ones that materials fabricated in industry undergo, which is the case of the Cu-Sn-Bi analyzed in this study.

In this context, the Cu9Bi phase can be an evolution of the previous $\mathrm{Cu}_{5} \mathrm{Bi}_{2}$ and $\mathrm{Cu}_{3} \mathrm{Bi}$ phases with progressive copper enrichment, or bismuth depletion, towards the stable pure copper, or copper-tin phase in the case of the present $\mathrm{Cu}-\mathrm{Sn}$-Bi system in equilibrium. Since EBSD is an analytical technique based on crystallographic data base derived from crystal symmetry information gathered mostly from thermodinamical equilibrium phases [23-27] EBSD, it is probable that its indexing procedure could retrieve the already known crystal symmetry of the pure copper phase and link it to the unknown metastable $\mathrm{Cu}_{9} \mathrm{Bi}$ phase, whose crystal symmetry probably is somewhat similar to the one of the pure copper phase, if the somehow small difference in chemical composition between $\mathrm{Cu}_{9} \mathrm{Bi}$ and pure copper phases is considered.

Microhardness test results confirm that bismuth rich coarser secondary phase particles are considerably softer (85.20 HV) than the aluminum rich matrix (99.60). Al-Si-Sn-Cu and Cu-Sn-Bi alloys present microstructural characteristics that favor their use in antifriction components. since they combine good hardness/ strength with good lubrication properties. As expected. in both alloys the matrix is considerably harder than the coarse second phase particles.

\section{Conclusion}

The results obtained din this study with the use of techniques such as optical microscopy and SEM presented the microstructure of the Al-Sn-Si-Cu and $\mathrm{Cu}-\mathrm{Sn}$-Bi alloys. composed by the aluminum rich and copper-tin rich matrix phases. respectively. and several particles of secondary phases. with different sizes. shapes. chemical compositions and functions. In the $\mathrm{Al}-\mathrm{Sn}-\mathrm{Si}-\mathrm{Cu}$ alloy several coarser particles of tin were observed mainly on the grain boundaries. According to the literature. these soft particles contribute to the good lubrication properties of this alloy. Smaller silicon rich particles. which present a dark gray color in SEM images. appeared both isolated and surrounded by the brighter tin rich phase. The main contribution of these silicon particles relies in their strengthening/hardening effect. Other phases were also identified by EBSD analysis: $\mathrm{Al}_{2} \mathrm{Cu}(\theta) \cdot \mathrm{Al}_{2} \mathrm{CuMg}(\mathrm{S})$ and $\mathrm{Al}_{3} \mathrm{Fe}$. These phases can also contribute to strengthening. in the same sense as the silicon particles. The same techniques were used to analyze the $\mathrm{Cu}-\mathrm{Sn}-\mathrm{Bi}$. showing that its microstructure is composed by a coppertin (bronze) rich matrix with several secondary phase particles. Among these phases. relatively coarse bismuth rich particles were observed. mainly on the grain boundaries. These particles are supposed to contribute to the good lubricity of this material in antifriction components applications. Smaller copper rich particles were also observed by SEM with higher magnifications (around $30.000 \mathrm{X}$ ) and identified by EDS, WDS and EBSD. Although in equilibrium copper and bismuth are immiscible, the specific technical literature reports that metastable phases of the type $\mathrm{CuXBiY}$ can appear in the $\mathrm{Cu}$-Bi system and in this context according to the WDS results these small particles correspond to the $\mathrm{Cu}_{9} \mathrm{Bi}$ phase, that can be an evolution of the previous $\mathrm{Cu}_{5} \mathrm{Bi}_{2}$ and $\mathrm{Cu}_{3} \mathrm{Bi}$ phases with progressive copper enrichment, or bismuth depletion, towards the stable pure copper, or copper-tin phase in the case of the present $\mathrm{Cu}-\mathrm{Sn}$-Bi system in equilibrium phase, if the somehow small difference in chemical composition between $\mathrm{Cu}_{9} \mathrm{Bi}$ and pure copper phases is considered. $\mathrm{Al}-\mathrm{Si}-\mathrm{Sn}-\mathrm{Cu}$ and $\mathrm{Cu}-\mathrm{Sn}$-Bi alloys show microstructural characteristics that enable their application in antifriction components. since they present at the same time good hardness/strength with good lubrication properties. The results demonstrate indeed that in these alloys the matrix is considerably harder than the coarse secondary phase particles.

\section{References}

1. MarroccoT, Driver LC, Harris SJ, McCartney DG (2006) J Therm Spray Technol 4: 634-639.

2. Yuan G, Zhang X, Lou Y, Li Z Trans (2003) Nonferrous Met Soc China 4: 774-780.

3. Osório WR, Spinelli JE, Cheung N, Garcia A (2006) The effects of a eutectic modifier on microstructure and surface corrosion behavior of Al-Si hypoeutectic alloys. Mater Sci Eng A 420: 179-186.

4. Ali MS, Reed PAS, Syngellakis S, Moffat A, Perrin C (2006) Mater Sci Forum. 519-521.

5. Feyzullahoglu E (2011) Ind Lubric Tribol 63(5): 350-358.

6. Cruz KAS, Cheung N, Garcia A (2008) Tecnol Met Mater 4(4): 21-26.

7. Perrone A, Zocco A, Rosa H, Zimmermann R, Bersani M (2002) Mater Sci Eng C 22: 465-468.

8. Yuan GC, Li ZJ, Lou YX, Zhang XM (2000) Mater Sci Eng A 280: 108-115.

9. Liu PI, Shang JK (2001) J Mater Res 16(6): 1651-1659.

10. La Fontaine A, Keast VJ (2006) Mater Charact 57: 424-429.

11. Saxton DM, Carpenter JM, Sevenski GW, Schmitt H, Andler G (2008) US Patent No. 2008/0166578 A1.

12. (2011) ASTM E 3-11. Standard Guide for Preparation of Metallographic Specimens. American Society for Testing Materials p 13.

13. (2011) ASTM E 407-07e1. Standard Practice for Microetching Metals and Alloys. American Society for Testing Materials p 23.

14. Andrews S, Rückert M, J Material (2006) 12: 3-6.

15. (2005) ISO 6507-1 Metallic materials -- Vickers hardness test -- Part 1: Test method. International Organization for Standardization p 19.

16. Chakrabarti DJ, Laughlin DE (1984) The Bi-Cu (Bismuth-Copper) System. Bulletin of Alloy Phase Diagrams 5: 148-155.

17. Duscher G, Chisholm MF, Alber U, Rühle M (2004) Bismuth induced embrittlement of copper grain boundaries. Nature Materials 3: 621-626.

18. Schweinfest R, Paxton AT, Finnis MW (2004) Bismuth embrittlement of copper is an atomic size effect. Nature, 432: 1008-1011.

19. Yan M, Luzzi DE, Vitek V, Acklnad GJ, Methfessel M, et al. (1993) Interatomic forces and atomic structure of grin boundaries in copperbismuth alloys. Physical review B 47: 5571-5582.

20. Niemelä JA (1986) thermodynamic evaluation of the copper-bismuth and copper-lead systems. Calphad 10: 77-89. 
21. Porter DA, Easterling KE (1981) Phase Transformations in Metals and Alloys, Van Nostrand Reinhold Company Ltd. Nova York 1st edition pp 446.

22. Abbashian R, Abbashian L, Reed-Hill RE (2009) Physical Metallurgy Principles. Cencage Learning Stamford 4th edition pp. 750.

23. Schwartz AJ, Kumar M, Adams BL (2000) Electron Backscatter Diffraction in Materials Science. Kluwer academic Plenum Publishers, New York, USA, pp. 339.

24. Stojakovic D (2012) Electron backscatter diffraction in materials characterization. Processing and Application of Ceramics 6: 1-13.
25. Wilkinson AJ (1997) Electron Diffraction Based techniques in Scanning Electron Microscopy of Bulk Materials. Micron 28: 279-308.

26. Courtas S, Grégoire M, Fedrspiel X, Bicaïs-Lepinay N, Wyon C (2006) Electron Back Scattered diffraction (EBSD) use and applications in newest technologies development. Microelectronics Reliability 46: 1530-1535.

27. Young-jun, C, Hjelen J, Roven HJ (2012) Application of EBSD technique to ultrafine grained and nanostructured materials processed by severe plastic deformation: Sample preparation, parameters optimization and analysis. Transactions of Nonferrous Metals Society of China 22: 18011809.

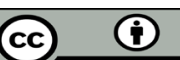

This work is licensed under Creative Commons Attribution 4.0 License

To Submit Your Article Click Here: Submit Article

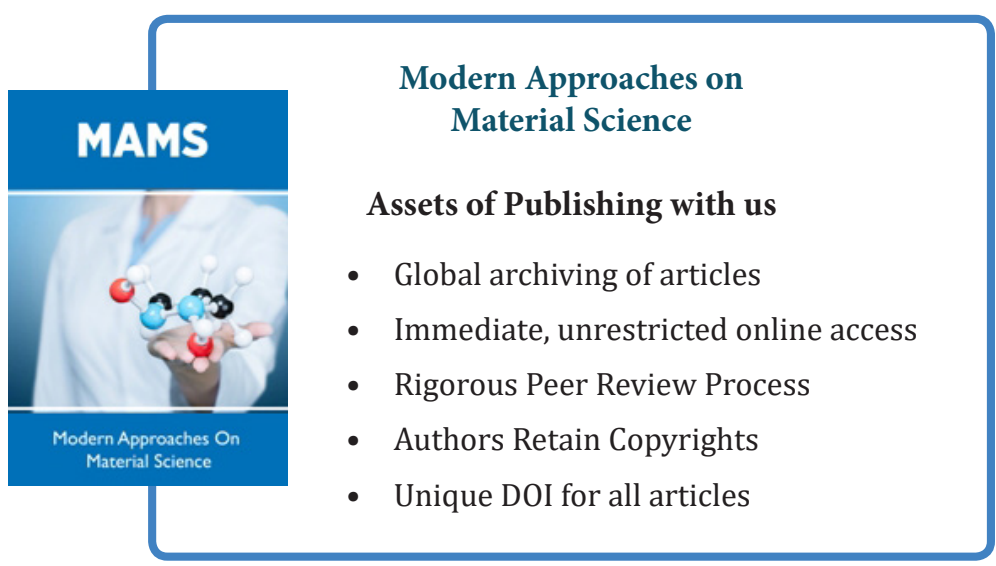

